\title{
Influence of photobiomodulation therapy on root development of rat molars with open apex and pulp necrosis
}

Ivana Maria ZACCARA(a)

Alexander Pompermayer JARDINE(a) Letícia Boldrin MESTIERI(a)

Ramiro Martins QUINTANA(a)

Luciano JESUS(a)

Maria Stella MOREIRA(b)

Fabiana Soares GRECCA ${ }^{(a)}$

Manoela Domingues MARTINS(a)

Patrícia Maria Poli KOPPER(a) (D)

(a) Universidade Federal do Rio Grande do Sul - UFRGS, School of Dentistry, Graduate program, Porto Alegre, RS, Brazil.

(b) Universidade Ibirapuera - UNIB, School of Dentistry, São Paulo, SP, Brazil.

Declaration of Interests: The authors certify that they have no commercial or associative interest that represents a conflict of interest in connection with the manuscript.

Corresponding Author:

Patricia Maria Poli Kopper

E-mail: patricia.kopper@ufrgs.br

https://doi.org/10.1590/1807-3107bor-2019.vol33.0084

Submitted: January 24, 2019

Accepted for publication: June 25, 2019

Last revision: July 31, 2019
Abstract: This study aimed to evaluate the role of photobiomodulation $(\mathrm{PBM})$ in apexification and apexogenesis of necrotic rat molars with an open apex. Rat molars were exposed to the oral environment for 3 weeks. Canals were rinsed with $2.5 \% \mathrm{NaOCl}$ and 17\% EDTA, filled with antibiotic paste and sealed. After 7 days, canals were rinsed and divided into six groups $(\mathrm{n}=6)$ : mineral trioxide aggregate (MTA); blood clot (BC); human dental pulp stem cells (hDPSC); MTA+PBM; BC+PBM; and hDPSC+PBM. In hDPSC groups, a $1 \%$ agarose gel scaffold was used. Two groups were not exposed: healthy tooth+PBM $(n=6)$, healthy tooth $(n=3)$; and one was exposed throughout the experiment: necrotic tooth $(n=3)$. In PBM groups, irradiation was performed with aluminum gallium indium phosphide (InGaAlP) diode laser for 30 days within 24-h intervals. After that, the specimens were processed for histological and immunohistochemical analyses. Necrotic tooth showed greater neutrophil infiltrate $(\mathrm{p}<0.05)$. Necrotic tooth, healthy tooth, and healthy tooth+PBM groups showed absence of a thin layer of fibrous condensation in the periapical area. All the other groups stimulated the formation of a thicker layer of fibers $(p<0.05)$. All groups formed more mineralized tissue than necrotic tooth $(p<0.05)$. PBM associated with MTA, BC, or hDPSC formed more mineralized tissue $(p<0.05)$. MTA+PBM induced apexification $(\mathrm{p}<0.05)$. Rabbit polyclonal anti-bone sialoprotein (BSP) antibody confirmed the histological findings of mineralized tissue formation, and hDPSC groups exhibited higher percentage of BSP-positive cells. It can be concluded that PBM improved apexification and favored apexogenesis in necrotic rat molars with an open apex.

Keywords: Dental Pulp; Low-Level Light Therapy; Stem Cells.

\section{Introduction}

Teeth with pulp necrosis and an open apex have been traditionally treated with calcium hydroxide paste and, more recently, with mineral trioxide aggregate (MTA) ${ }^{1,2}$ These procedures aim to induce an apical barrier (apexification). However, there is no increase in root length and width, and the tooth may be weak and susceptible to fracture. ${ }^{2}$ Therefore, 
the ideal treatment for necrotic immature permanent teeth would be the employment of tissue engineering procedures to replace damaged tissues, which would favor dentin and pulp regeneration, promoting the increase in root length and width, and, consequently, in tooth maintenance. ${ }^{3}$ Thus, knowledge about the biological processes involving triad stem cells (SCs), scaffold (biomaterials), growth factors, and other biostimulatory/biomodulatory procedures is necessary for regenerative endodontic treatment. ${ }^{4}$

Human dental pulp stem cells (hDPSCs) isolated from healthy teeth have shown proliferative potential and have been studied for several regenerative purposes. ${ }^{5,6}$ These cells exhibit immunoregulatory capacity, suppressing the $\mathrm{T}$ cell immune response both in vitro and in vivo. ${ }^{7}$ Based on that, $\mathrm{SCs}$ are good candidates for the treatment of mesenchymal tissue diseases and show a potential use in xenogeneic environments. ${ }^{8}$ Furthermore, the immunosuppressive properties of hDPSC could make them attractive for use in animal transplants. ${ }^{8}$

SCs need a structure to support them and to provide their viability when they are transplanted to another environment. In this context, biomaterials play a key role by providing a three-dimensional (3D) model to promote new tissue formation. ${ }^{9}$ Biomaterials may be used as scaffold for SC support and as synthetic microenvironments in terms of chemical composition, physical structure, and biological properties that affect proliferation and differentiation of SCs. ${ }^{10}$ Nowadays, natural and synthetic scaffolds have been used in tissue engineering. ${ }^{11,12}$ Among natural scaffolds, agarose gel presents favorable characteristics for transplantation procedures, for being bioinert and nontoxic, decreasing potential immune rejection in rats. ${ }^{12,13,14}$

Photobiomodulation (PBM) therapy is a form of light therapy that utilizes non-ionizing light sources, including lasers, and promotes biostimulatory effects on different cell types, both in vitro and in vivo. ${ }^{15,16,17,18}$ Thus, PBM stimulates cell growth, increases cell metabolism, improves cell regeneration, promotes tissue response, and accelerates dentin regeneration after pulp exposure. ${ }^{15,16,17,18}$ Also, PBM improves dentoalveolar-derived mesenchymal SC (including hDPSC) viability and proliferation, allowing odonto/ osteogenic differentiation. ${ }^{15,16,17,18}$ Based on that, PBM therapy could be added as the fourth element of the tissue engineering triad (SCs, scaffolds, and growth factors).

Taking into account the possibility of using tissue engineering to favor the increase in root length and width, it is justified to apply PBM aiming to stimulate cell proliferation and differentiation, and to accelerate dentin formation and pulp cell regeneration. Therefore, the present study aimed to evaluate the role of PBM in apexification and apexogenesis of rat molars with an open apex and pulp necrosis using different treatment protocols. The null hypothesis is that PBM does not favor apexification and apexogenesis in necrotic rat molars with an open apex.

\section{Methodology}

The study was approved by the Institutional Review Board for Animal Studies of the Federal University of Rio Grande do Sul (process \#27827). Also, the Institutional Review Board of the same University (CAAE 37252614.3.0000.5347) approved the use of hDPSCs obtained from four permanent third molars with incomplete root formation.

\section{Animals}

Twenty-four rats (Rattus norvegicus albinus, rodentia mammalia - Wistar lineage), weighing 150 to $200 \mathrm{~g}$ and approximately 4 weeks old, were randomly divided into nine groups, according to treatment protocols for rat molars, and two were used for confirmation of the experimental protocols (Figure 1).

\section{Experimental procedures}

The animals were anesthetized intraperitoneally with ketamine $80 \mathrm{mg} / \mathrm{kg}$ and xylazine $20 \mathrm{mg} / \mathrm{kg}$ (Syntec, Santana do Parnaíba, Brazil). A device maintained the rats' mouths opened during the experimental procedures. ${ }^{19}$ Cavities were drilled on the central portion of the occlusal surface of the right and left mandibular first molars using a 1011HL bur (KGSorensen, Cotia, Brazil) to expose the dental pulp. Root canal lengths were determined by radiographic images, as previously described, ${ }^{19}$ and the pulp tissues were removed with a \#10 K-file (Dentsply Maillefer, 


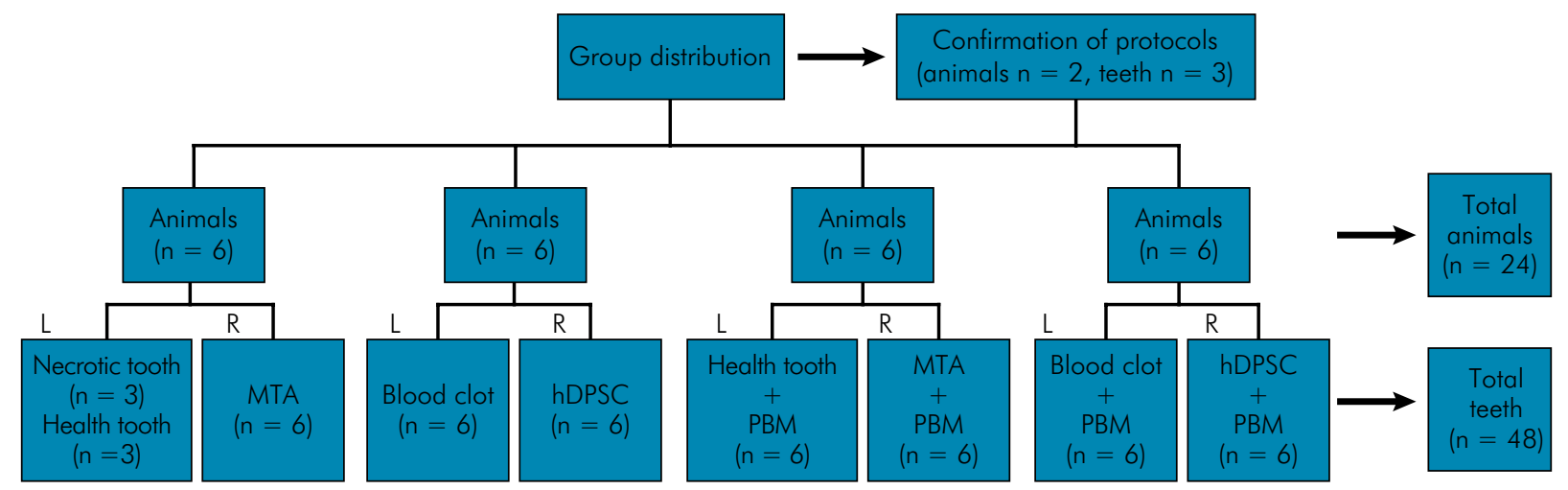

L: left tooth. R: right tooth. Necrotic tooth (pulp necrosis without treatment); healthy tooth (vital pulp without treatment); MTA (pulp necrosis treated with MTA plug); blood clot (pulp necrosis with blood clot induction); hDPSC (pulp necrosis with hDPSC transplantation); healthy tooth+PBM (vital pulp and PBM therapy); MTA+PBM (pulp necrosis treated with MTA plug and PBM therapy); blood clot+PBM (pulp necrosis with blood clot induction and PBM therapy); and hDPSC+PBM (pulp necrosis with hDPSC transplantation and PBM therapy).

Figure 1. Flowchart illustrating group distribution according to the treatment protocols for rat molars.

Ballaigues, Switzerland) and the canals were left open for 3 weeks - time required for confirmation of pulp necrosis. ${ }^{19}$ After that, the root canals were irrigated with $2.5 \%$ sodium hypochlorite $(\mathrm{NaOCl}$ ) (CIENTEC - Science and Technology Foundation, Porto Alegre, Brazil) and 17\% EDTA (CIENTEC - Science and Technology Foundation, Porto Alegre, Brazil), using a syringe and a 29-G side-vented NaviTip irrigation needle (Ul-tradent, South Jordan, UT) calibrated $1 \mathrm{~mm}$ short of the working length. The root canals were then dried and filled with triple antibiotic paste $(50 \mathrm{mg}$ metronidazole, $50 \mathrm{mg}$ ciprofloxacin, and $50 \mathrm{mg}$ minocycline per milliliter of propylene glycol). Finally, the teeth were sealed with amalgam. Intracanal medicament was maintained for 7 days. ${ }^{20}$ Thereafter, the coronal sealing was removed and the canals were irrigated with $2.5 \% \mathrm{NaOCl}$, followed by $17 \%$ EDTA.

The necrotic tooth group (negative control) included teeth that were left open throughout the experimental period and that did not receive any treatment procedure, except for pain control. The healthy tooth group (positive control) included teeth that were not subjected to any procedure. For MTA groups, the canals were filled with an MTA plug (Angelus, Londrina, Brazil) along their extension. For blood clot (BC) groups, the apical foramina were overpassed $1 \mathrm{~mm}$ beyond the root total length and instrumented with a \#10 K-file, promoting BC induction. For hDPSC groups, the apical foramina were also overpassed and instrumented, and then small blocks of agarose gel scaffold with the hDPSCs were transplanted into the canals. The healthy tooth+PBM, MTA+PBM, BC+PBM, and hDPSC+PBM groups received 30 days of $\mathrm{PBM}$ therapy, as described below. After the procedures, all teeth from the experimental and necrotic tooth groups were sealed with MTA and amalgam. After every experimental procedure, $50 \mathrm{mg} / \mathrm{kg}$ of opioid analgesic (Tramal 50; Pfizer Indústria Farmacêutica, Guarulhos, Brazil) was used for pain control. Two animals ( $\mathrm{n}=3$ teeth) were used to confirm necrosis induction, BC formation, and transplantation of hDPSCs. These animals were euthanized immediately after the procedures (Figure 2).

\section{Stem cell characterization and 3D culture}

The apical papilla of the extracted teeth was removed to reach the pulp tissue. The pulp was then isolated from the apical opening using $\mathrm{H}$ files (Dentsply Maillefer, Ballaigues, Switzerland) and stored in a culture dish $(35 \times 10 \mathrm{~mm})$ containing Alpha Modification Minimum Essential Eagle's Medium ( $\alpha$-MEM; Sigma-Aldrich, St. Louis, USA) supplemented with 10\% fetal bovine serum (FBS; Gibco, Waltham, USA) and 1\% penicillin and streptomycin (PenStrep; Gibco, Waltham, USA). Each pulp tissue was sectioned into fragments of 

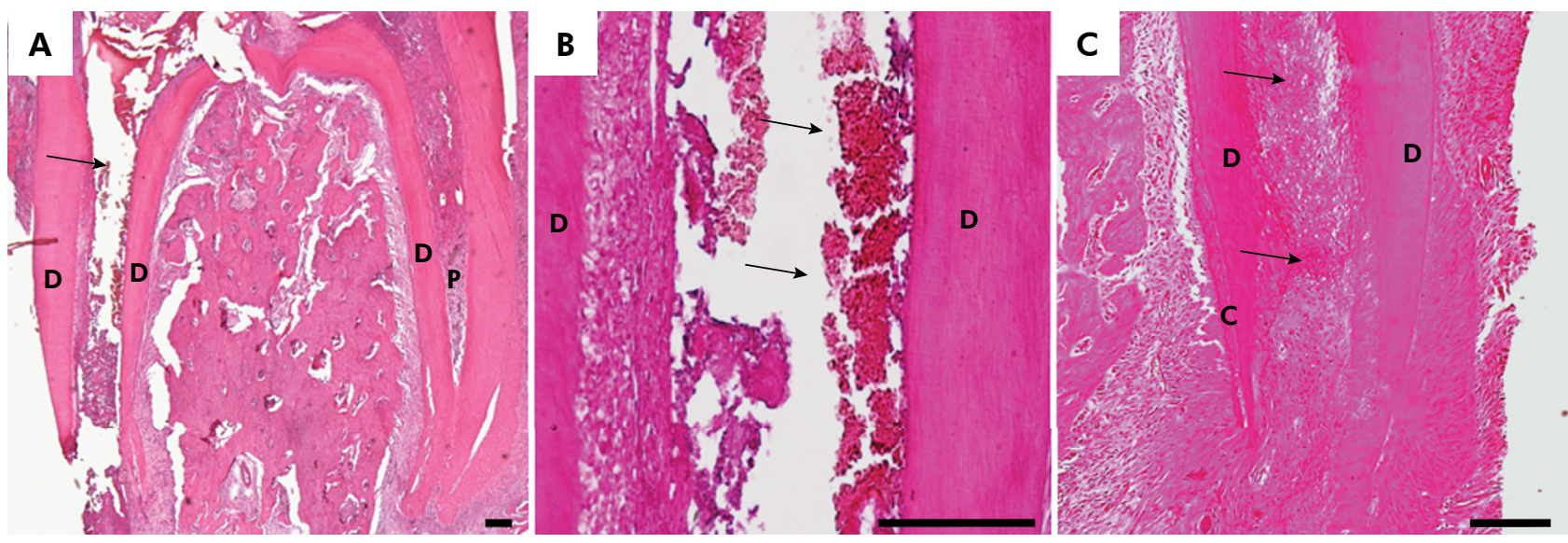

D: dentin; RC: root canal; C: cementum. Scale bars $=100 \mu \mathrm{m}$.

Figure 2. Histological aspects of teeth of animals euthanized immediately after the procedures to confirm the efficacy of protocols. (A) Root canal subjected to pulp removal (arrow) (H\&E, 40x magnification). (B) Blood clot induction. Note the presence of blood cells within the canal (arrow) (H\&E, 200x magnification). (C) Transplantation of hDPSCs (arrows) (H\&E, 100x magnification).

approximately $1 \mathrm{~mm}^{3}$ and kept in supplemented $\alpha$-MEM at $37^{\circ} \mathrm{C}, 95 \%$ humidity, and $5 \% \mathrm{CO}^{2}$. The culture medium was replaced $24 \mathrm{~h}$ after pulp collection and at every $48 \mathrm{~h}$ to obtain explants of hDPSCs. After reaching the confluence ( 70 to $90 \%$ of cells) of the plate, the cells were trypsinized (Trysin; Sigma-Aldrich) for the next passage.

An aliquot of cells was evaluated by flow cytometry in the second passage (P2) to observe the expression of typical levels of mesenchymal SC surface markers. The analysis revealed positive staining for surface markers of mesenchymal SCs (STRO1, CD146, and CD105; Santa Cruz Biotechnology, Dallas, USA) and negative staining for markers of hematopoietic SCs (CD45 and CD14; Santa Cruz Biotechnology, Dallas, USA). Additionally, the multilineage differentiation potential of hDPSCs, up to 14 days, was confirmed by culturing the cells in osteogenic, adipogenic, and chondrogenic differentiation media.

A pilot study defined the ideal concentration of agarose gel for transplantation of hDPSCs to the root canals of the rat molars, leading to the selection of a $1 \%$ agarose solution (Sigma-Aldrich) for preparation of the $3 \mathrm{D}$ culture, using $\alpha$-MEM. After preparation, $1,000 \mu \mathrm{L}$ of this solution was pipetted into a Petri dish. After agarose solidification, $1 \times 10^{6}$ of hDPSCs, cultured in $\alpha$-MEM supplemented with $1 \%$ penicillin and streptomycin and regular 10\% FBS, were seeded onto the dish. Forty-eight hours after seeding, the areas with more quantity of cells in the scaffolds were transplanted into the root canals of rat molars. The small blocks, with similar root canal conformation, were transplanted within the canals of hDPSC and hDPSC+PBM groups.

\section{Laser irradiation}

Considering that PBM therapy could have systemic effects, PBM groups were distributed among the same animals (Figure 1). Irradiation started immediately after each treatment using an InGaAlP diode laser (MMOptics, São Carlos, Brazil) operating with the following parameters: wavelength of $660 \mathrm{~nm}$, power of $100 \mathrm{~mW}$, spot size of $0.3 \mathrm{~cm}^{2}$, energy density of $3 \mathrm{~J} / \mathrm{cm}^{2}$, exposure time of 10 seconds, and energy of $1 \mathrm{~J}$ per point of application. Irradiation was performed on the buccal side of the tooth and was performed on 24-h intervals for 30 days, resulting in a total energy of $30 \mathrm{~J}$ on each tooth. Before each irradiation session, the animals were anesthetized with isoflurane (Virbac do Brasil Indústria e Comércio Ltda, São Paulo, Brazil) diluted in oxygen (inhalant anesthetic with 3\% concentration) and the power of the laser equipment was checked (Laser Check; MMOptics, São Carlos, Brazil).

\section{Histological analysis}

The animals were euthanized by isoflurane overdose (BioChimico, Itatiaia, Brazil) after 30 days 
of treatment. The jaws were dissected for histological and immunohistochemical evaluation.

The specimens were fixed in $10 \%$ buffered formaldehyde for $24 \mathrm{~h}$, decalcified in Morse's solution ( $20 \%$ sodium citrate $+50 \%$ formic acid) for 20 weeks, rehydrated in ascending concentrations of ethanol, and embedded in paraffin. Three-micromillimeter sections were cut and stained with hematoxylineosin or processed for immunohistochemistry. The sections were selected from the visualization of the central portion of the root, including the apex and the periapical region, and were analyzed under light microscopy (Olympus BX40 Microscope; Olympus Optical, Tokyo, Japan). The features related to inflammatory infiltrate, fibrous condensation, apex conformation, deposition of mineralized tissue on the root canal walls, and formation of mineralized barrier were evaluated by three blinded and calibrated examiners (interrater reliability: $\mathrm{k}=0.89, \mathrm{p}<0.001$ ).

Evaluation of cellular events and fibrous condensation was adapted from Tavares et al. ${ }^{21}$ Inflammatory infiltrate cells were analyzed separately (neutrophils, lymphocytes, eosinophils, macrophages, and giant cells) and scored as absent (0), mild (1), moderate (2), or severe (3). Fibrous condensation was classified as absent (0), thin layer (1), or thick layer (2). The conformation of foraminal opening was classified as divergent (0) or convergent (1). The deposition of mineralized tissue on the root canal walls was scored as absent (0), thin layer (1), or thick layer (2), and the formation of mineralized barrier was scored as absent (0) or present (1).

\section{Immunohistochemical analysis}

The $3-\mu \mathrm{m}$ sections were placed on silanized plates and heated in an incubator for $30 \mathrm{~min}$ at $80^{\circ} \mathrm{C}$. Thereafter, they were deparaffinized in xylol and rehydrated in alcohol and PBS for $5 \mathrm{~min}$. Antigenic recovery, endogenous peroxidase blocking, and protein blocking were carried out according to the following protocol, respectively: water bath for $35 \mathrm{~min}$ at $94^{\circ} \mathrm{C}$ in citrate buffer $(\mathrm{pH}=6.0), 5 \%$ hydrogen peroxide in absolute methanol (in the dark for $20 \mathrm{~min}$ ), and 5\% skimmed milk in PBS for $20 \mathrm{~min}$. After that, the sections were washed in cycles with distilled water and finally with PBS. The sections were then incubated with rabbit polyclonal anti-bone sialoprotein (BSP, 1:500; Abcam, Cambridge, United Kingdom) at 4 to $8^{\circ} \mathrm{C}$ overnight. Thereafter, the sections were washed 3 times in PBS and incubated with secondary conjugated antibodies and goat anti-rabbit IgG antibody (AP132p; Merck Milipore, Millerica, USA) for $90 \mathrm{~min}$, as recommended by the manufacturer. The sections were rinsed 3 times with PBS for 5 min; immunoreactivity was visualized after incubation with 3,30-diaminobenzidine (DAB) solution (Dako Liquid DAB Substratehromogen System; Dako, Carpinteria, USA); and, finally, the sections were counterstained with hematoxylin. Immunohistochemical control was performed by replacing the primary antibodies with nonimmune serum. Bone marrow was used as the positive control for BSP.

The analysis of BSP immunoexpression along the root canals was performed, describing the pattern of protein distribution on root canal walls as absent (0), thin layer (1), or thick layer (2), and the cells inside the root canal as absent (0), $0-50 \%$ of positive cells (1), or $50-100 \%$ of positive cells (2).

\section{Statistical analysis}

The data were compared by the Kruskal-Wallis test, followed by Dunn's post-hoc test. The significance level was set at $5 \%$. Statistical analysis was performed using GraphPad Prism 5.0 (GraphPad, La Jolla, USA).

\section{Results}

\section{Histological analysis}

The data are summarized and illustrated in Figures 3 and 4 . The necrotic tooth group, without treatment, presented more pronounced neutrophil infiltrate $(\mathrm{p}<0.05)$ (Figures $3 \mathrm{~A}$ and $4 \mathrm{~A})$. Mild lymphocyte infiltrate was observed in all groups $(p>0.05)$ (Figure 3B). Eosinophil, macrophage, and giant cell infiltrate were not observed.

Necrotic tooth, healthy tooth, and healthy tooth+PBM groups showed absence of a thin layer of fibrous condensation in the periapical area. All other groups stimulated the formation of a thicker layer of fibers $(p<0.05)$ (Figure 3C). Regarding the 
A

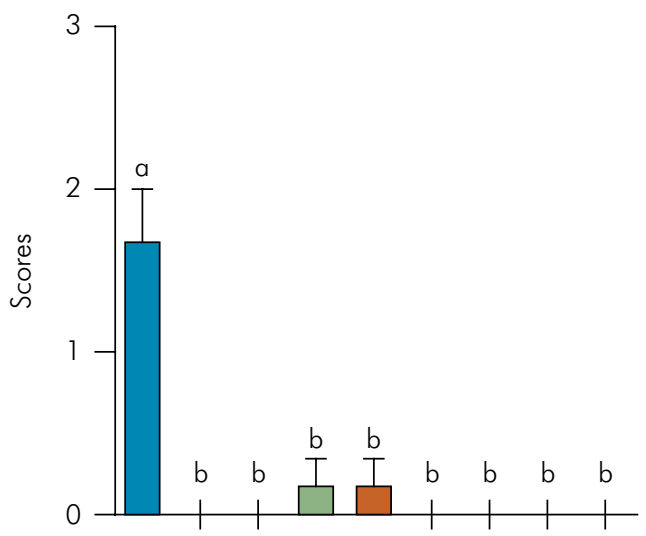

C

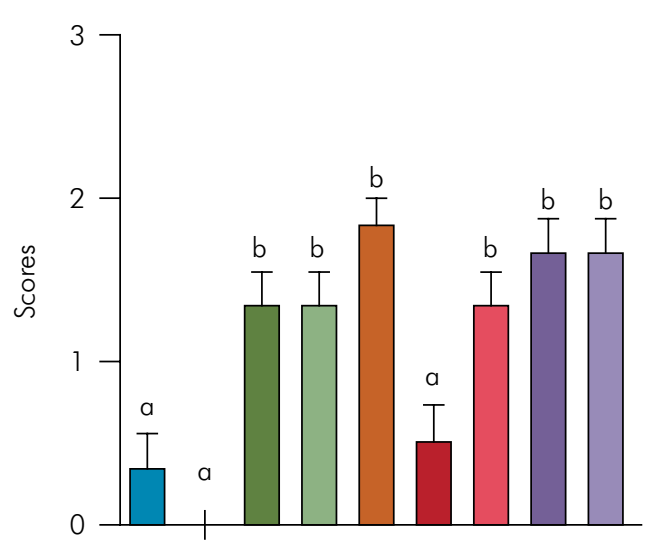

$\mathrm{E}$

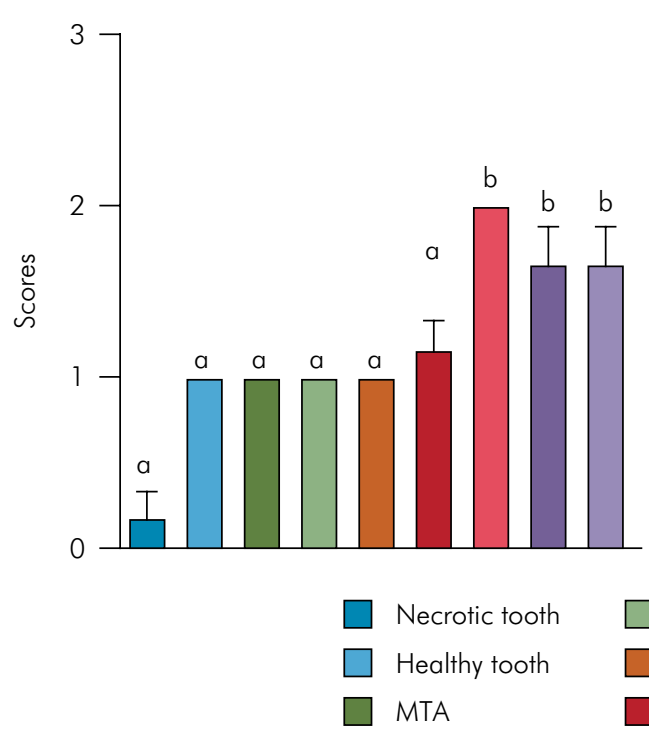

B

Lymphocytes
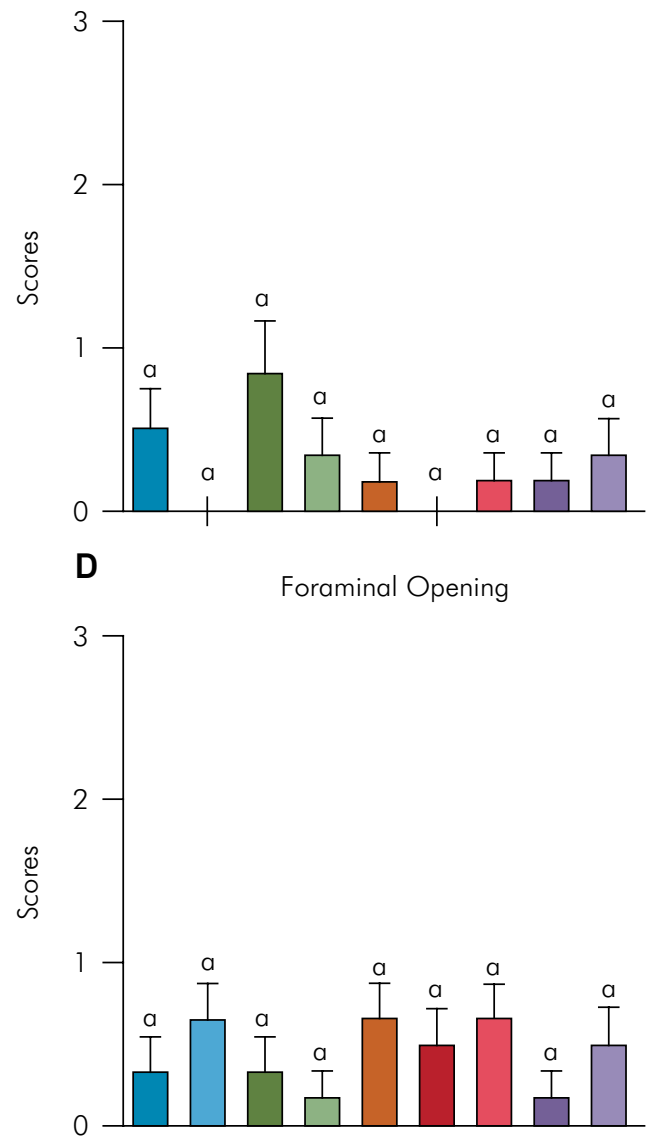

$\mathbf{E}$

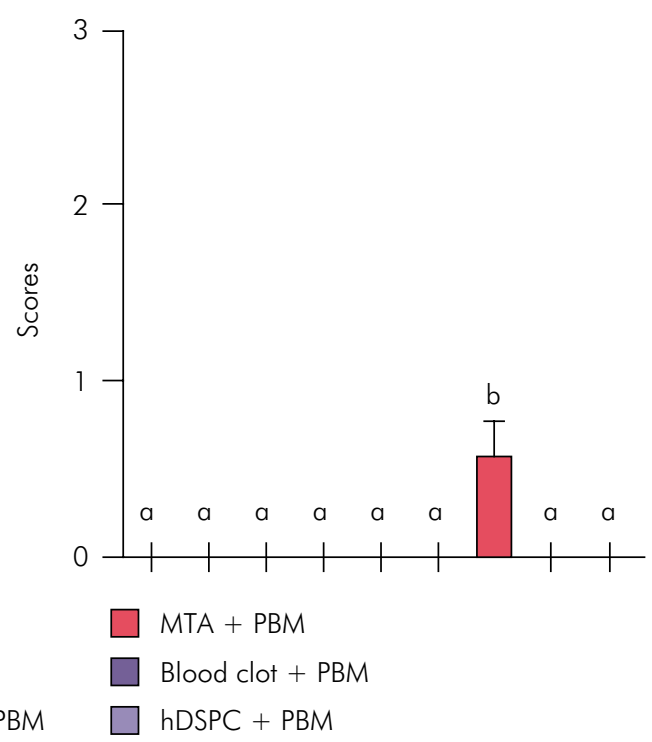

Different lowercase letters indicate statistically significant difference $(p<0.05)$.

Figure 3. Graphic representation of the comparison between groups for (A) neutrophils, (B) lymphocytes, (C) fibrous condensation, (D) foraminal opening, (E) mineralized tissue formation, and (F) mineralized barrier. 


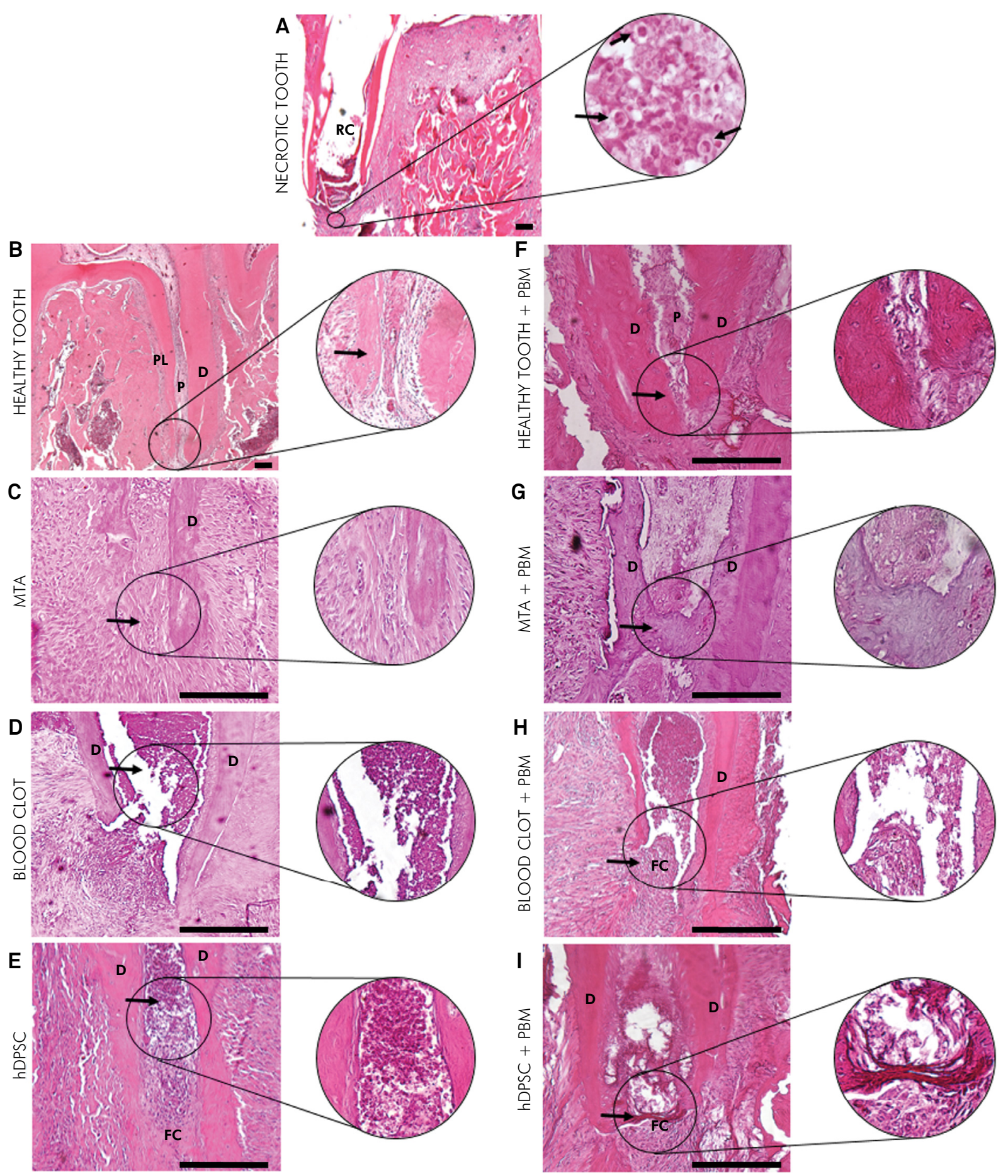

D: dentin; P: pulp; PL: periodontal ligament; RC: root canal; FC: fibrous condensation. Scale bars $=100 \mu \mathrm{m}$.

Figure 4. Histological aspects of each group. (A) Necrotic tooth group. Moderate neutrophil infiltrate (arrows) (H\&E, 40x magnification). (B) Healthy tooth group. Natural root formation (arrow) (H\&E, 40x magnification). (C) MTA group. Thin layer of fibrous condensation in the periapical area (arrow) (H\&E, 200x magnification). (D) Blood clot group. Cell concentration of blood clot in the root canal (arrow) (H\&E, 200x magnification). (E) hDPSC group. Presence of transplanted cells within the root canal (arrow) (H\&E, 200x magnification). (F) Healthy tooth+PBM group. Natural root formation exhibiting complete root development (arrow) (H\&E, 200x magnification). (G) MTA+PBM group. Formation of mineralized barrier (arrow) (H\&E, 200x magnification). (H) Blood clot+PBM group. Thin layer of fibrous condensation in the periapical area (arrow) (H\&E, 200x magnification). (I) hDPSC+PBM group. Presence of mineralized tissue on root canal walls (arrow) and thin layer of fibrous condensation in the apical portion (asterisk) (H\&E, 200x magnification). Disc-shaped images represent higher magnification: 1000x (A) or 400x magnification (B, C, D, E, F, G, H, I). 
root apex conformation, all groups presented similar results $(p>0.05)$ (Figure 3D). All groups formed more mineralized tissue than did the necrotic tooth group ( $p$ < 0.05). PBM associated with MTA, BC, and hDPSC induced more mineralized tissue formation compared to non-irradiated groups $(\mathrm{p}<0.05)$ (Figure 3E). The MTA+PBM group was the only one that induced apexification, being statistically different from the others $(\mathrm{p}<0.05)($ Figure 3F)

\section{BSP immunostaining analysis}

Figures 5 and 6 illustrate and summarize the immunoexpression of BSP. All groups showed positive reaction to $\mathrm{BSP}$, which was more evident in the inner portion of root canal dentin. Necrotic tooth, healthy tooth, MTA, BC, hDPSC, and healthy tooth+PBM groups showed a thin layer of BSP-positive labeling on the root canal walls (Figures 5A, B, C, D, E, F, and 6A). Meanwhile, when PBM therapy was applied concomitantly with MTA, BC, and hDPSC, a thicker layer of BSP-positive labeling was noted on the root canal walls $(\mathrm{p}<0.05)$ (Figures 5G, H, I, and 6A). Besides, the MTA+PBM group exhibited complete apexification associated with thick BSP labeling in the new mineralized matrix (Figure 5G).

BSP analysis of cells inside the root canal revealed that hDPSC and hDPSC+PBM groups exhibited higher percentage (50-100\%) of BSP-positive cells than did the necrotic tooth, MTA, and MTA+PBM groups $(p<0.05)$. However, there was no difference between healthy tooth, BC, healthy tooth+PBM, and BC+PBM groups ( $p>0.05)$ (Figures 5 and 6B).

\section{Discussion}

Tissue engineering and regenerative medicine have become important research areas. ${ }^{11}$ In endodontics, biological procedures using the tissue engineering triad have demonstrated potential to replace damaged structures, such as dentin and pulp complex..$^{22,23}$ In vitro studies demonstrated the effective influence of PBM on the proliferation and differentiation of SCs. ${ }^{4,24}$ Animal models have been employed to investigate the biological response of teeth with an open apex. ${ }^{19,25}$ However, the present study was the first to evaluate, in vivo, the influence of PBM therapy for 30 days on root apexification and apexogenesis in a model of induced pulp necrosis. The main results show that PBM therapy favors apexification and apexogenesis in necrotic rat molars with an open apex, rejecting the null hypothesis. PBM improved dentin tissue formation when associated with MTA, BC, and hDPSC in histological and immunohistochemical analyses.

MTA is considered the gold standard for the treatment of teeth with an open apex and pulp necrosis, inducing apexification. ${ }^{2}$ This is an attractive bioceramic material, as it provides chemical signals for odontogenic/dentinogenic periapical tissue regeneration. ${ }^{26,27}$ MTA properties are frequently related to the release of calcium and hydroxyl ions during hydration of the material. These ions act as chemical signals that alkalinize the microenvironment, leading to the formation of mineralized tissue. ${ }^{28}$ The current findings show that the MTA group presented mineralized tissue formation, similar to what had already been reported. ${ }^{26}$ Interestingly, PBM associated with MTA accelerated the process of mineralized tissue deposition (observed by its thicker layer) compared to the MTA group. These findings are in line with those of previous studies that described positive effects of PBM associated with calcium hydroxide or MTA. ${ }^{29,30}$ Moreover, the present study shows that only the MTA+PBM group was able to induce apical mineralized barrier formation in 30 days, being the first to describe the effect of MTA and diode laser irradiation on necrotic teeth with an open apex.

Regarding apexogenesis, regenerative endodontics aims to repair dental pulp-like tissues using two possible strategies: cell homing or cell transplantation. ${ }^{23} \mathrm{BC}$ is considered a source of SCs and could be used as a natural scaffold to support the in-growth of a new tissue into the empty canal space. Some studies have shown that root canal disinfection combined with blood clot formation could induce dentin deposition on the root canal walls and increase root length. ${ }^{31}$ This happens because $\mathrm{BC}$ originates from the vascular component of the periapical tissue and employs the host's endogenous cells to achieve tissue repair/regeneration. ${ }^{23}$ In addition, BC presents growth factors that stimulate differentiation, 


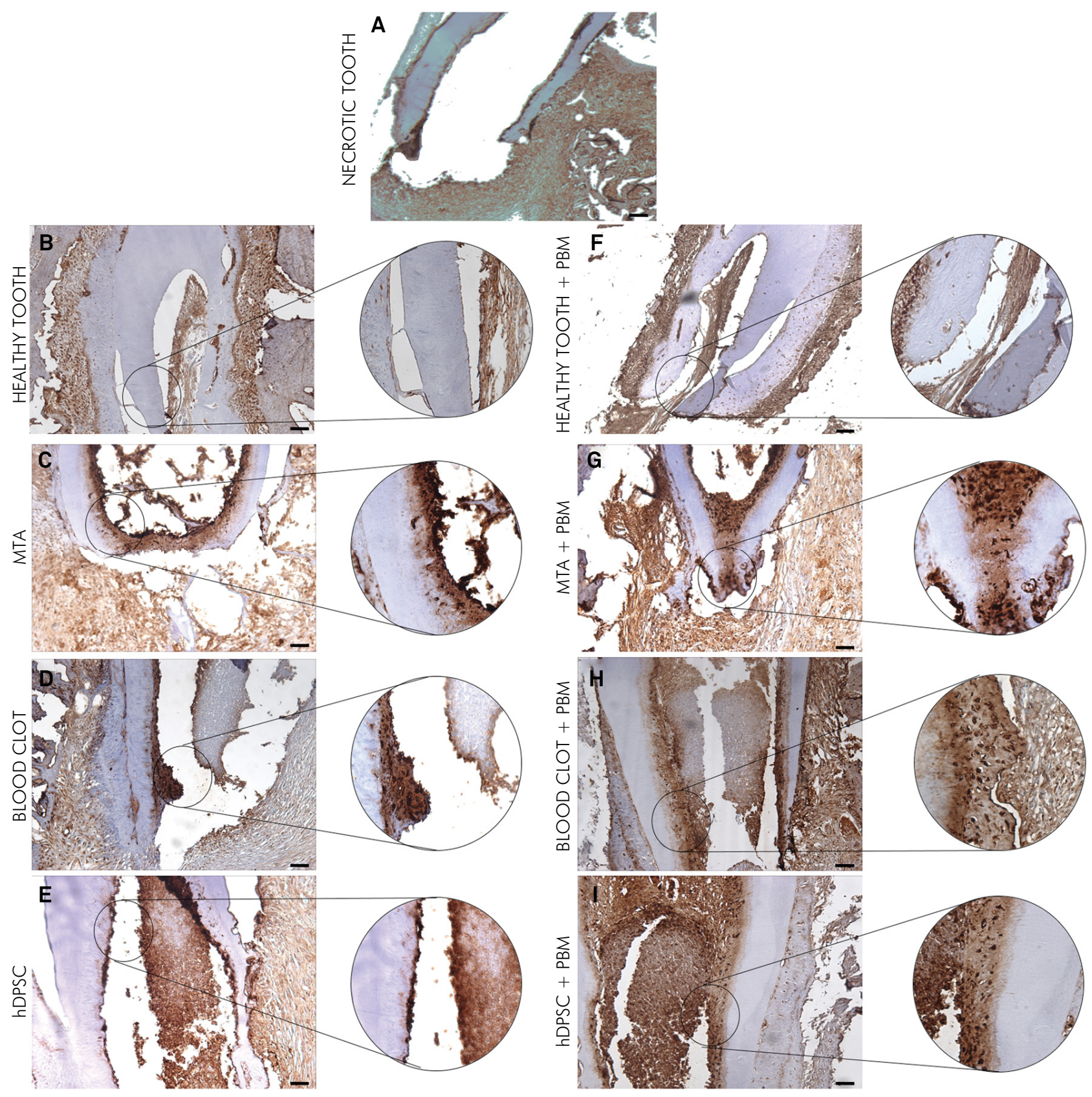

Disc-shaped images represent higher magnification (HRP, 400x magnification). D: dentin; P: pulp; PL: periodontal ligament; RC: root canal; FC: fibrous condensation. Scale bars $=100 \mu \mathrm{m}$.

Figure 5. BSP immunoexpression of all experimental groups. Thin layer of BSP-positive dentin in the inner portion of root canal walls in the (A) necrotic tooth group (HRP, 40x magnification), (B) healthy tooth group (HRP, 40x magnification), (C) MTA group (HRP, 40x magnification), (D) blood clot group (HRP, 40x magnification), (E) hDPSC group (HRP, 40x magnification), (F) healthy tooth+PBM group (HRP, 40x magnification). Presence of a thicker layer of BSP-positive dentin on root canal walls in the (G) MTA+PBM group (HRP, 40x magnification), (H) blood clot+PBM group (HRP, 40x magnification), (I) hDPSC+PBM group (HRP, 40x magnification).

growth, and maturation of fibroblasts, odontoblasts, and cementoblasts. ${ }^{26}$ Thus, in accordance with the literature, the present study shows that the BC technique was able to form mineralized tissue on the root canal walls ${ }^{32}$ and increase it when PBM was associated. A previous report of this association has been described in the literature; however, the $\mathrm{BC}+\mathrm{PBM}$ protocol was applied immediately after the 
A

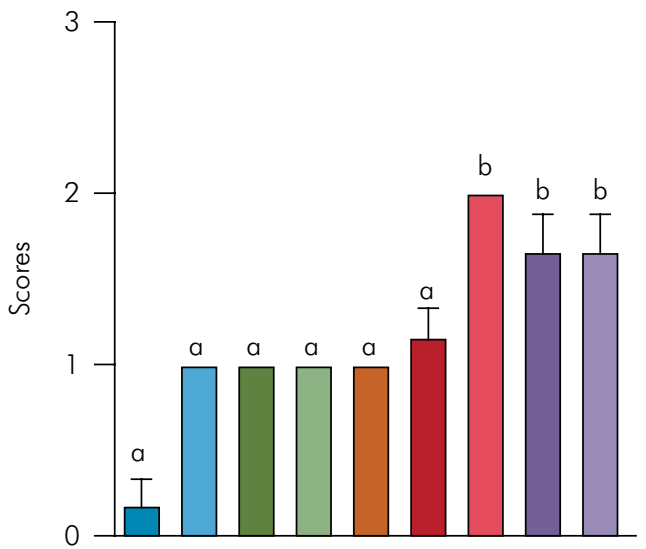

Necrotic tooth

Healthy tooth

MTA
B Cellular BSP marker

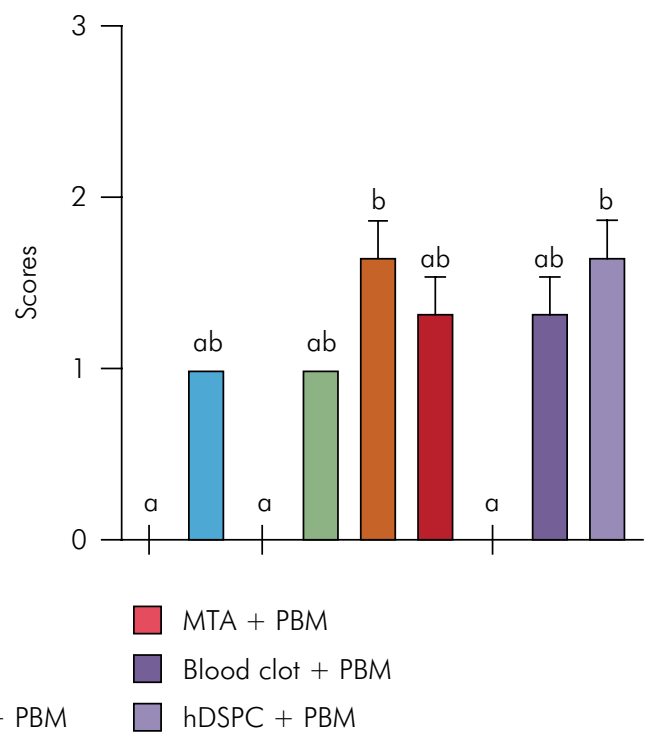

Different lowercase letters indicate statistically significant difference $(p<0.05)$.

Figure 6. Graphic representation of the comparison between groups for immunoexpression of BSP marker for (A) Root walls BSP marker. (B) Cellular BSP marker.

dental pulp removal, resulting in a dental pulp-like tissue with vessels, nerves, odontoblast-like cell layer, and perivascular SCs. ${ }^{25}$ Furthermore, mineralized tissue formation along the root canal walls was not described..$^{25}$ The present results draw attention to cases of pulp necrosis and open apex, which are common in the endodontic clinical practice, showing that the use of PBM associated with BC stimulation may promote an increase in root length and width, consequently expanding the chance of tooth maintenance.

On the other hand, the transplantation of SCs into the root canal may be a promising alternative for apexogenesis therapy. Different scaffolds have been analyzed as support to SCs during the dentin-pulp complex regeneration process. ${ }^{2,31,33,34}$ In the present study, hDPSCs were associated with agarose scaffold due to the possibility of modifying its consistency according to the agarose concentration, facilitating its manipulation and application within the root canal. Agarose has already been used to regenerate osseous, cartilaginous, and neural tissues. ${ }^{12,13,14}$

Furthermore, the final irrigation with $17 \%$ EDTA performed herein plays an important role. The EDTA solution induces the dentin to release growth factors that provide cell differentiation and expression of dentin sialoprotein (DSPP). This could be justified by the variety of growth factors present in the EDTA-soluble fraction that remains in direct contact with the demineralized human dentin extracellular matrix. ${ }^{11}$ The growth factors observed were transforming growth factor beta 1 (TGF-131), fibroblast growth factor 2 (FGF-2), bone morphogenetic protein 2 (BMP-2), platelet-derived growth factor (PDGF), and placental growth factor (PGF) ${ }^{11}$ Moreover, these molecules are effective at very low concentrations and induce cellular response, recruitment, proliferation, and differentiation, as well as mineralization. ${ }^{35}$

hDPSCs without PBM therapy promoted a thin layer of mineralized tissue along the root canal walls. When associated with PBM, the layer became thicker, improving tissue regeneration along the root canal walls. Recent studies have demonstrated that the transplantation of hDPSCs into the root canal, without PBM therapy, promotes the formation of a vascularized pulp-like tissue, odontoblast-like cells, and newly generated dentin, but they have not evaluated mineralized tissue deposition. ${ }^{36}$ In this study, as in previous in vitro studies, ${ }^{37}$ the BSP marker 
confirmed the differentiation potential of hDPSCs. To the best of our knowledge, this is the first in vivo report of mineralized tissue deposition associated with hDPSC transplantation and PBM on root canal walls of necrotic teeth with an open apex.

The results show that PBM therapy increased mineralized tissue formation when associated with MTA, BC, and hDPSC transplantation. Therefore, it would be possible to infer that PBM can be used as an adjuvant procedure for teeth with pulp necrosis and an open apex, aiming at apexification or apexogenesis. In fact, PBM therapy accelerates dentinogenesis and apexogenesis of healthy immature permanent teeth..$^{29,38,39}$ Furthermore, clinical investigations have demonstrated that PBM is an effective alternative for pulpotomy and pulp capping, presenting favorable tissue reactions and satisfactory tissue healing., ${ }^{4,25,30}$ The positive effects of PBM on tissue mineralization can occur due to its capacity to improve cellular metabolism, to increase cell proliferation and collagen synthesis, to favor angiogenesis, accelerating the healing process, and to promote analgesic and reparative effects. ${ }^{15,16}$ In this context, in vitro studies have indicated the cumulative effect of applications of irradiation to promote cell proliferation, differentiation, and mineralized tissue formation..$^{40}$ In addition, PBM increases osteoblast proliferation and gene expression of osteoblast markers, such as alkaline phosphatase, runt-related transcription factor 2 (Runx-2), osteocalcin (OC), type I collagen (COL I), type III collagen (COL III), BSP, transforming growth factor beta 2 (TGF- $\beta 2$ ), bone morphogenetic proteins (BMPs), and fibroblast growth factor (FGF). ${ }^{39,41}$

To confirm the potential of mineralized tissue formation in the experimental groups, the expression of BSP was verified. This marker is highly specific to mineral tissues, including bone, mineralized cartilage, dentin, and cementum. ${ }^{42}$ The current findings show that, when PBM therapy was performed with MTA, BC, or hDPSC, a thicker layer of mineralized tissue was positive for BSP. Complete apexification, associated with strong BSP labeling in the new mineralized matrix, was also observed in the MTA+PBM group. BSP labeling results corroborated the histological findings of mineralized tissue formation. Previous studies have also demonstrated that PBM improved bone formation and up-regulated the expression of growth factors and genes related to bone cell differentiation, which leads to the stimulation of cell proliferation in the pulp-dentin complex. ${ }^{33}$ However, it is important to emphasize that BSP labeling was more evident in the inner portion of the root canal dentin. This finding is in line with those reported in previous studies, in which BSP played an important role in the early stages of matrix formation and mineralization, making the mantle matrix dentin more evident than the tubular dentin. ${ }^{43}$

The experimental model employed provided an adequate insight into the effect of PBM therapy on apexification and apexogenesis of necrotic teeth with an open apex. Daily PBM therapy is important to maintain the biostimulatory effect and it can be performed in the clinical setting, but patients would have to be able to visit the dentist's office more frequently. It is important to point out that to confirm the present findings, future clinical studies on the effect of PBM on regenerative endodontic therapy should be performed.

\section{Conclusion}

In rat teeth with pulp necrosis and an open apex, PBM therapy improved tissue response to apexification with MTA and also favored the increase in root length and width (apexogenesis) associated with $\mathrm{BC}$ induction or hDPSC transplantation. Thus, PBM might be recommended as an adjuvant therapy to accelerate apical healing and the root development process. However, new clinical studies are needed to validate the current findings.

\section{Acknowledgments}

The authors thank the staff of the School of Dentistry at the Federal University of Rio Grande do Sul for permitting the use of their Oral Pathology laboratory.

The authors Ivana Maria Zaccara, Alexander Pompermayer Jardine, Letícia Boldrin Mestieri, and Ramiro Martins Quintana were funded by the Coordination for the Improvement of Higher Education Personnel (CAPES) agency, Brazil. 


\section{References}

1. Camilleri J, Formosa L, Damidot D. The setting characteristics of MTA Plus in different environmental conditions. Int Endod J. 2013 Sep;46(9):831-40. https://doi.org/10.1111/iej.12068

2. Nicoloso GF, Pötter IG, Rocha RO, Montagner F, Casagrande L. A comparative evaluation of endodontic treatments for immature necrotic permanent teeth based on clinical and radiographic outcomes: a systematic review and meta-analysis. Int J Paediatr Dent. 2017 May;27(3):217-27. https://doi.org/10.1111/ipd.12261

3. Wang Y, Zhao Y, Jia W, Yang J, Ge L. Preliminary study on dental pulp stem cell-mediated pulp regeneration in canine immature permanent teeth. J Endod. 2013 Feb;39(2):195-201. https://doi.org/10.1016/i.joen.2012.10.002

4. Marques MM, Diniz IM, Cara SP, Pedroni AC, Abe GL, D'Almeida-Couto RS, et al. Photobiomodulation of dental derived mesenchymal stem cells: a systematic review. Photomed Laser Surg. 2016 Nov;34(11):500-8. https://doi.org/10.1089/pho.2015.4038

5. Gronthos S, Mankani M, Brahim J, Robey PG, Shi S. Postnatal human dental pulp stem cells (DPSCs) in vitro and in vivo. Proc Natl Acad Sci USA. 2000 Dec;97(25):13625-30. https://doi.org/10.1073/pnas.240309797

6. Costa AM, Bueno DF, Martins MT, Kerkis I, Kerkis A, Fanganiello RD, et al. Reconstruction of large cranial defects in nonimmunosuppressed experimental design with human dental pulp stem cells. J Craniofac Surg. 2008 Jan;19(1):204-10. https://doi.org/10.1097/scs.0b013e31815c8a54

7. Abumaree M, Al Jumah M, Pace RA, Kalionis B. Immunosuppressive properties of mesenchymal stem cells. Stem Cell Rev. 2012 Jun;8(2):375-92. https://doi.org/10.1007/s12015-011-9312-0

8. Lin CS, Lin G, Lue TF. Allogeneic and xenogeneic transplantation of adipose-derived stem cells in immunocompetent recipients without immunosuppressants. Stem Cells Dev. 2012 Oct;21(15):2770-8. https://doi.org/10.1089/scd.2012.0176

9. Hout WM, Molen ABM, Breugem CC, Koole R, Van Cann EM. Reconstruction of the alveolar cleft: can growth factor-aided tissue engineering replace autologous bone grafting? A literature review and systematic review of results obtained with bone morphogenetic protein-2. Clin Oral Investig. 2011 Jun;15(3):297-303. https://doi.org/10.1007/s00784-011-0547-6

10. Piva E, Silva AF, Nör JE. Functionalized scaffolds to control dental pulp stem cell fate. J Endod. 2014 Apr;40(4 Suppl):S33-40. https://doi.org/10.1016/i.joen.2014.01.013

11. Galler KM, D'Souza RN, Hartgerink JD, Schmalz G. Scaffolds for dental pulp tissue engineering. Adv Dent Res. 2011 Jul;23(3):333-9. https://doi.org/10.1177/0022034511405326

12. Suzawa Y, Kubo N, Iwai S, Yura Y, Ohgushi H, Akashi M. Biomineral/agarose composite gels enhance proliferation of mesenchymal stem cells with osteogenic capability. Int J Mol Sci. 2015 Jun;16(6):14245-58. https://doi.org/10.3390/ijms160614245

13. Aurand ER, Lampe KJ, Bjugstad KB. Defining and designing polymers and hydrogels for neural tissue engineering. Neurosci Res. 2012 Mar;72(3):199-213. https://doi.org/10.1016/i.neures.2011.12.005

14. Pakulska MM, Ballios BG, Shoichet MS. Injectable hydrogels for central nervous system therapy. Biomed Mater. 2012 Apr;7(2):024101. https://doi.org/10.1088/1748-6041/7/2/024101

15. Salate AC, Barbosa G, Gaspar P, Koeke PU, Parizotto NA, Benze BG, et al. Effect of In-Ga-Al-P diode laser irradiation on angiogenesis in partial ruptures of Achilles tendon in rats. Photomed Laser Surg. 2005 Oct;23(5):470-5. https://doi.org/10.1089/pho.2005.23.470

16. Souza TO, Mesquita DA, Ferrari RA, Pinto Junior DS, Correa L, Bussadori SK, et al. Phototherapy with low-level laser affects the remodeling of types I and III collagen in skeletal muscle repair. Lasers Med Sci. 2011 Nov;26(6):803-14. https://doi.org/10.1007/s10103-011-0951-9

17. AlGhamdi KM, Kumar A, Moussa NA. Low-level laser therapy: a useful technique for enhancing the proliferation of various cultured cells. Lasers Med Sci. 2012 Jan;27(1):237-49. https://doi.org/10.1007/s10103-011-0885-2

18. Anders JJ, Lanzafame RJ, Arany PR. Low-level light/laser therapy versus photobiomodulation therapy. Photomed Laser Surg. 2015 Apr;33(4):183-4. https://doi.org/10.1089/pho.2015.9848

19. Scarparo RK, Dondoni L, Böttcher DE, Grecca FS, Rockenbach MI, Batista EL Jr. Response to intracanal medication in immature teeth with pulp necrosis: an experimental model in rat molars. J Endod. 2011 Aug;37(8):1069-73. https://doi.org/10.1016/i.joen.2011.05.014

20. Hoshino E, Kurihara-Ando N, Sato I, Uematsu H, Sato M, Kota K, et al. In-vitro antibacterial susceptibility of bacteria taken from infected root dentine to a mixture of ciprofloxacin, metronidazole and minocycline. Int Endod J. 1996 Mar;29(2):125-30. https://doi.org/10.1111/j.1365-2591.1996.tb01173.x

21. Tavares CO, Böttcher DE, Assmann E, Kopper PM, de Figueiredo JA, Grecca FS, et al. Tissue reactions to a new mineral trioxide aggregate-containing endodontic sealer. J Endod. 2013 May;39(5):653-7. https://doi.org/10.1016/i.joen.2012.10.009

22. Hargreaves KM, Diogenes A, Teixeira FB. Treatment options: biological basis of regenerative endodontic procedures. J Endod. 2013 Mar;39(3 Suppl):S30-43. https://doi.org/10.1016/i.joen.2012.11.025

23. Eramo S, Natali A, Pinna R, Milia E. Dental pulp regeneration via cell homing. Int Endod J. 2018 Apr;51(4):405-19. https://doi.org/10.1111/iej.12868 
24. Borzabadi-Farahani A. Effect of low-level laser irradiation on proliferation of human dental mesenchymal stem cells; a systemic review. J Photochem Photobiol B. 2016 Sep;162:577-82. https://doi.org/10.1016/i.jphotobiol.2016.07.022

25. Moreira MS, Diniz IM, Rodrigues MF, Carvalho RA, Carrer FCA, Neves II, et al. In vivo experimental model of orthotopic dental pulp regeneration under the influence of photobiomodulation therapy. J Photochem Photobiol B. 2017 Jan;166:180-6. https://doi.org/10.1016/i.jphotobiol.2016.11.022

26. Nagy MM, Tawfik HE, Hashem AA, Abu-Seida AM. Regenerative potential of immature permanent teeth with necrotic pulps after different regenerative protocols. J Endod. 2014 Feb;40(2):192-8. https://doi.org/10.1016/i.joen.2013.10.027

27. Bonte $E$, Beslot $A$, Boukpessi T, Lasfargues JJ. MTA versus $\mathrm{Ca}(\mathrm{OH}) 2$ in apexification of non-vital immature permanent teeth: a randomized clinical trial comparison. Clin Oral Investig. $2015 \mathrm{Jul} ; 19(6): 1381-8$. https://doi.org/10.1007/s00784-014-1348-5

28. Gandolfi MG, Spagnuolo G, Siboni F, Procino A, Rivieccio V, Pelliccioni GA, et al. Calcium silicate/calcium phosphate biphasic cements for vital pulp therapy: chemical-physical properties and human pulp cells response. Clin Oral Investig. 2015 Nov;19(8):2075-89. https://doi.org/10.1007/s00784-015-1443-2

29. Fekrazad R, Seraj B, Ghadimi S, Tamiz P, Mottahary P, Dehghan MM. The effect of low-level laser therapy (810 nm) on root development of immature permanent teeth in dogs. Lasers Med Sci. 2015 May;30(4):1251-7. https://doi.org/10.1007/s10103-014-1588-2

30. Fernandes AP, Lourenço Neto N, Marques NCT, Moretti ABS, Sakai VT, Silva TC, et al. Clinical and radiographic outcomes of the use of Low-Level Laser Therapy in vital pulp of primary teeth. Int J Paediatr Dent. 2015 Mar;25(2):144-50. https://doi.org/10.1111/ipd.12115

31. Yang JW, Zhang YF, Wan CY, Sun ZY, Nie S, Jian SJ, et al. Autophagy in SDF-1 $\alpha$-mediated DPSC migration and pulp regeneration. Biomaterials. 2015 Mar;44:11-23. https://doi.org/10.1016/i.biomaterials.2014.12.006

32. Lovelace TW, Henry MA, Hargreaves KM, Diogenes A. Evaluation of the delivery of mesenchymal stem cells into the root canal space of necrotic immature teeth after clinical regenerative endodontic procedure. J Endod. 2011 Feb;37(2):133-8. https://doi.org/10.1016/i.joen.2010.10.009

33. Mangione F, EzEldeen M, Bardet C, Lesieur J, Bonneau M, Decup F, et al. Implanted dental pulp cells fail to induce regeneration in partial pulpotomies. J Dent Res. 2017 Nov;96(12):1406-13. https://doi.org/10.1177/0022034517725523

34. Palma PJ, Ramos JC, Martins JB, Diogenes A, Figueiredo MH, Ferreira P, et al. Histologic evaluation of regenerative endodontic procedures with the use of chitosan scaffolds in immature dog teeth with apical periodontitis. J Endod. 2017 Aug;43(8):1279-87. https://doi.org/10.1016/i.joen.2017.03.005

35. Zhang R, Cooper PR, Smith G, Nör JE, Smith AJ. Angiogenic activity of dentin matrix components. J Endod. 2011 Jan;37(1):26-30. https://doi.org/10.1016/i.joen.2010.08.042

36. Cordeiro MM, Dong Z, Kaneko T, Zhang Z, Miyazawa M, Shi S, et al. Dental pulp tissue engineering with stem cells from exfoliated deciduous teeth. J Endod. 2008 Aug;34(8):962-9. https://doi.org/10.1016/i.joen.2008.04.009

37. Matsui S, Tsujimoto Y, Matsushima K. Stimulatory effects of hydroxyl radical generation by Ga-Al-As laser irradiation on mineralization ability of human dental pulp cells. Biol Pharm Bull. 2007 Jan;30(1):27-31. https://doi.org/10.1248/bpb.30.27 PMID:17202654

38. Toomarian L, Fekrazad R, Tadayon N, Ramezani J, Tunér J. Stimulatory effect of low-level laser therapy on root development of rat molars: a preliminary study. Lasers Med Sci. 2012 May;27(3):537-42. https://doi.org/10.1007/s10103-011-0935-9

39. Arany PR, Cho A, Hunt TD, Sidhu G, Shin K, Hahm E, et al. Photoactivation of endogenous latent transforming growth factor- $\beta 1$ directs dental stem cell differentiation for regeneration. Sci Transl Med. 2014 May;6(238):238ra69. https://doi.org/10.1126/scitranslmed.3008234

40. Zaccara IM, Ginani F, Mota-Filho HG, Henriques ÁC, Barboza CA. Effect of low-level laser irradiation on proliferation and viability of human dental pulp stem cells. Lasers Med Sci. 2015 Dec;30(9):2259-64. https://doi.org/10.1007/s10103-015-1803-9

41. Tim CR, Bossini PS, Kido HW, Malavazi I, von Zeska Kress MR, Carazzolle MF, et al. Effects of low-level laser therapy on the expression of osteogenic genes during the initial stages of bone healing in rats: a microarray analysis. Lasers Med Sci. 2015 Dec;30(9):2325-33. https://doi.org/10.1007/s10103-015-1807-5

42. Chen J, McCulloch CA, Sodek J. Bone sialoprotein in developing porcine dental tissues: cellular expression and comparison of tissue localization with osteopontin and osteonectin. Arch Oral Biol. 1993 Mar;38(3):241-9. https://doi.org/10.1016/0003-9969(93)90034-J

43. Ganss B, Kim RH, Sodek J. Bone sialoprotein. Crit Rev Oral Biol Med. 1999;10(1):79-98. https://doi.org/10.1177/10454411990100010401 